\title{
Replication report: No spontaneous alternation in gerbils
}

\author{
GARY GREENBERG* \\ Wichita State University, Wichita, Kans. 67208
}

Twelve male Mongolian gerbils were tested for spontaneous alternation in a $\mathrm{T}$ maze, a $U$ maze, and a parallel-arm maze. Alternation rates did not exceed chance in any of the mazes. Albino rats, on the other hand, did alternate in the $T$ and $U$ mazes but not in the parallel-arm maze. It is suggested that the vestibular system of the gerbil may be associated with their failure to display spontaneous alternation.

In a recent study, Douglas, Mitchell, \& Kentala (1972) demonstrated that maze configuration was an important variable for the appearance of spontaneous alternation. Rats did alternate in a conventional $\mathrm{T}$ maze and in a U maze but did not do so in a parallel-arm maze. These authors suggested that "the two choice alleys must be spatially distinct if they are to elicit alternations [p. 286]."

The present study was an attempt to replicate the results of Douglas et al with another species, the Mongolian gerbil, Meriones unguiculatus. Several factors point to the necessity of (a) replications and (b) replications with other species if we are to eventually formulate "general theories" of behavior. As early as 1950 , Beach pointed out that contemporary psychology (ca. 1950) was really a psychology of rat learning. A recent review of the literature (Cassel, 1971) revealed that Beach's lesson has not really been heeded, since white rat research has been supplemented merely by a great deal of pigeon research; two species hardly enable us to formulate general behavioral laws. As Cassel pointed out, "The strongest argument for the use of a larger variety of species is based on doubt about how well the behavior of the few species studied represents the behavior of all animals. Whether or not general laws of behavior can be discovered by studying only a few species is an empirical question. It is, however, a question which cannot be answered in the absence of data derived from a wide range of species [p. 4]."

Using a different species is, therefore, in order for psychological research, and replications are similarly warranted. In recent years a new species, the gerbil, has found its way into psychology laboratories. This organism is easy to maintain, reproduces readily, and is amenable to our laboratory regimens. With these comments in mind, we attempted to replicate the study of Douglas et al (1972) with gerbils.

\footnotetext{
*Sponsored by R. C. Haygood, Arizona State University, who
} takes editorial responsibility for the manuscript.

\begin{abstract}
METHOD
Subjects

Twelve male Mongolian gerbils, Meriones unguiculatus, were obtained from the Tumblebrook Farm and housed in pairs in standard cages. Food was available ad lib and was supplemented twice weekly with lettuce leaves. The Ss were 180 days old at the time of testing.
\end{abstract}

\section{Apparatus}

The three mazes were identical to those described by Douglas et al (1972), except that in the present study they were unpainted. The mazes were bottomless, with the floor being a Formica table top covered with newspaper. Sliding doors separated the startboxes from the main alley and the main alley from the maze arms. The latter doors had holes through which $S$ jumped to enter an arm.

\section{Procedure}

The procedure followed was also identical to that of Douglas et al (1972, pp. 285-286) with one exception: The newspaper floor on which the mazes rested was changed between animals. Briefly, Ss were given two identical trials in each of the three mazes. The maze sequence was randomly determined. The experiment was then replicated until each $S$ had been tested six times in each of the three mazes, for a total of 18 observations per animal.

\section{RESULTS AND DISCUSSION}

Table 1 shows the totals, means, and percent of alternations displayed in each of the mazes. As can be seen, the animals did not alternate beyond chance levels in any of the mazes.

This suggested two possibilities: (1) Gerbils are unlike other animals tested for spontaneous alternation or (2) our procedures were not identical to those of Douglas et al (1972). To decide between these possibilities, we replicated the study with 90-day-old Sprague-Dawley albino rats bred in our colony and reared in litter cages, with six Ss to a cage. As in the Douglas et al (1972) study, the rats did alternate in two of the mazes but not in the third, the parallel-arm maze. Table 1 also contains the corresponding figures for the rats. It can be seen that the rats alternated $68 \%$ and $70 \%$ of the time in the T maze and U maze, respectively, both of which were significantly different from chance $(t=$

Table 1

Alternation Scores Within Each Maze for Gerbils and Rats

\begin{tabular}{llccc}
\hline & Alternations & T Maze & U Maze & $\begin{array}{c}\text { Parallel- } \\
\text { Arm Maze }\end{array}$ \\
\hline \multirow{4}{*}{ Gerbils } & Mean & 2.92 & 2.92 & 2.75 \\
& Percent & 49 & 49 & 46 \\
& $t$ (p level) & -.22 & -.22 & .82 \\
& & $($ n.s.) & $($ n.s.) & $($ n.s.) \\
\multirow{4}{*}{ Rats } & Mean & 4.08 & 4.17 & 3.33 \\
& Percent & 68 & 70 & 56 \\
& $t$ (p level) & 2.72 & 3.39 & .77 \\
& & $(<.01)$ & $(<.005)$ & $($ n.s.) \\
\hline
\end{tabular}


2.72 and 3.39 , respectively, $\mathrm{df}=22, \mathrm{p}<.01$ in both instances) and at chance level (56\%) in the third maze.

Thus, we have no alternative but to conclude that, unlike rats, gerbils do not display spontaneous alternation, at least not in the three maze patterns used here. The reasons for the absence of this behavior are not known at this time, although one possibility may lie in the physiology of the animal. One theory of spontaneous alternation involves the role played by the vestibular system of the animal in making spatial direction alternation (Douglas, 1966). Thus, rats with middle ear disease were found to greatly reduce their incidence of spontaneous alternation. It has been established that audiogenic seizures in rats are associated with middle ear disease (Munn, 1950). We might, then, expect seizure-prone rats not to alternate or to alternate at a greatly reduced rate. This suggestion has significance for the present study in light of the presence of "spontaneous seizures" in some gerbil strains (Thiessen, Lindzey, \& Friend, 1968). These seizures are quite similar to the audiogenic seizures of rats, and both have been described as "epileptic-like." Some of our animals did display such seizures, although their results were discarded. However, the possibility remains that, since these seizures apparently have a genetic origin, gerbils may have a vestibular system that is congenitally impaired, and this impairment may be responsible for the absence of spontaneous alternation in this species.

\section{REFERENCES}

Beach. A. The snark was a boojum. American Psychologist, $1950,5,115-124$.

Cassel. C. A. The snark: Twenty years later. Paper read at meeting of the American Psychological Association, Washington, D.C.. 1971 .

Douglas, R. S. Spontaneous alternation and middle ear disease. Psychonomic Science, 1966, 4, 243-244.

Douglas, R. J., Mitchell, D., \& Kentala, D. Spontaneous alternation as a function of maze configuration. Psychonomic Science, 1972, 27, 285-286.

Munn, N. L. Handbook of psychological research on the rat. Boston: Houghton Mifflin, 1950.

Thiessen, D. D., Lindzey, G., \& Friend, H. C. Spontaneous seizures in the Mongolian gerbil, Meriones unguiculatus. Psychonomic Science, 1968, 11, 227-228.

(Received for publication December 4, 1972.) 